\title{
UMA PROPOSTA DE JOGO ASSISTIVO PARA DISPOSITIVOS MÓVEIS EM PROL DA INCLUSÃO DIGITAL DE DEFICIENTES VISUAIS
}

\author{
Maria Aparecida Pereira Junqueira', Luiz Filipe Cunha', Alex Fernandes da Veiga \\ Machado', Josimar Gonçalves Ribeiro Moreira ${ }^{2}$
}

'Departamento de Ciência da Computação - „2Departamento de Educação - Instituto Federal de Educação, Ciência e Tecnologia do Sudeste de Minas Gerais, Câmpus Rio Pomba (IFSEMG) - Rio Pomba, MG - Brasil.

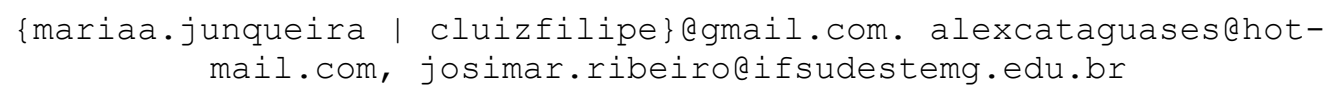

\begin{abstract}
Resumo. O avanço tecnológico tem possibilitado cada dia mais o acesso à informação por portadores de deficiência. Diversas aplicações vêm contribuindo para facilitar as atividades desenvolvidas por elas, quer seja em um computador ou até mesmo em tablets ou celulares. Para deficientes visuais já é possível, por exemplo, ler ou editar textos e usar o e-mail sozinhos, através do uso de sistemas operacionais especificos ou leitores eletrônicos. Apesar disto, observou-se que a indústria do entretenimento eletrônico não tem atingido este público, mantendo suas aplicações com elementos gráficos ao qual um cego não teria acesso. Portanto, foi desenvolvido um jogo de dominó mobile assistivo para este público, a fim de incluí-los no mundo do entretenimento virtual.
\end{abstract}

Palavras-chave: acessibilidade, pessoas com deficiência visual, jogo eletrônico.

\begin{abstract}
Technological advancement has made possible more each day access to information by the disabled people. Several applications have contributed to facilitate the activities developed by these people, whether on a personal computer or even on tablets or mobile phones. For the visually impaired it is possible, for example, read or edit text and use e-mail without the dependence on third parties, through the use of specific operating systems or electronic readers. Despite all advancement already occurred, it was observed that the electronic entertainment industry has not reached this audience keeping their applications with graphical elements to which a blind person would not have access. In this sense, it was developed a assistive domino mobile game for people of this deficiency, in order to provide fun times and also include them in the virtual world.
\end{abstract}

Keywords: accessibility, visually impaired, digital game.

\section{Introdução}

Vivemos em uma realidade onde a tecnologia virou parte de nosso cotidiano. Isso se dá devido a velocidade com que as informações são transmitidas nos meios tecnológicos. Com isso, muitos têm optado por um relacionamento cada vez mais digital. Pois assim, a distância não se torna um empecilho e o conhecimento fica a um passo para eles. 
Contudo, nem sempre o uso desses recursos é de fácil acesso, impedindo que uma parcela da população consiga interagir com os mesmos, provocando assim, uma exclusão digital ou social das mesmas. Pode parecer fácil entrar em uma página simples, como o Facebook, mas para uma pessoa com alguma limitação, pode ser uma tarefa bem complexa.

Outra forma de exclusão que se torna mais evidente é quando alguém com algum problema de visão é vítima de sites produzidos com letras minúsculas. Devido a situações como essas, nem sempre a acessibilidade aos ambientes virtuais é alcançada por todos. Dessa forma:

A acessibilidade é um processo dinâmico, associado não só ao desenvolvimento tecnológico, mas principalmente ao desenvolvimento da sociedade. Apresenta-se em estágios distintos, variando de uma sociedade para a outra, conforme seja a atenção dispensada à diversidade humana, por essa sociedade, à época. (TORRES, 2002, p.83)

Para que haja acessibilidade virtual é necessário que essa seja concedida para as pessoas de modo que elas consigam ter acesso pleno às informações disponibilizadas no meio. Esse é um dos problemas enfrentados pelos desenvolvedores quando projetam um sistema, já que eles devem suprir as necessidades pessoais não apenas com algum tipo de deficiência, como: idosos, pessoas com poucos recursos tecnológicos ou com baixo conhecimento sobre computadores ou internet, pois como relata (Dias 2003), " acessibilidade digital" possibilita oferecer acesso à diversos tipos de informes, independente de quem o solicita e da tecnologia utilizada. A transmissão da informação deve ser clara e objetiva, de modo que todos consigam usufruir e entendê-las.

Neste contexto, o jogo Blind Domino foi desenvolvido pelo grupo PET (Programa de Educação Tutorial), a fím de descobrir problemas enfrentados por cidadãos com deficiência visual no universo virtual e tentar apresentar alguma solução em relação ao desenvolvimento de aplicativos, inseridos nos moldes das tecnologias assistivas e da inclusão digital.

\section{Acessibilidade e Inclusão}

Por muito tempo, pessoas com deficiência foram tratados como uma parte exclusa da sociedade. A acessibilidade era reduzida. Porém, com o surgimento de leis federais que proporcionaram direitos e promoveram a inclusão no meio comum, eles passam a ter mais suporte adequado e novas possibilidades estão surgindo.

Conforme a empresa de pesquisa eMarketer publicou em 11 de dezembro de 2014, o número de usuários de Smartphones pelo mundo irá ultrapassar o valor de 2 bilhões no ano de 2016, de acordo com o gráfico (Figura 1) neste ano o número de telefones inteligentes será de mais de 1.91 bilhões ao redor do mundo e a mesma ainda aponta que terá um crescimento de mais $12,6 \%$ para o ano de 2016 totalizando aproximadamente 2.16 bilhões de usuários de Smartphones. 
CBIE-LACLO 2015

Anais do XXI Workshop de Informática na Escola (WIE 2015)

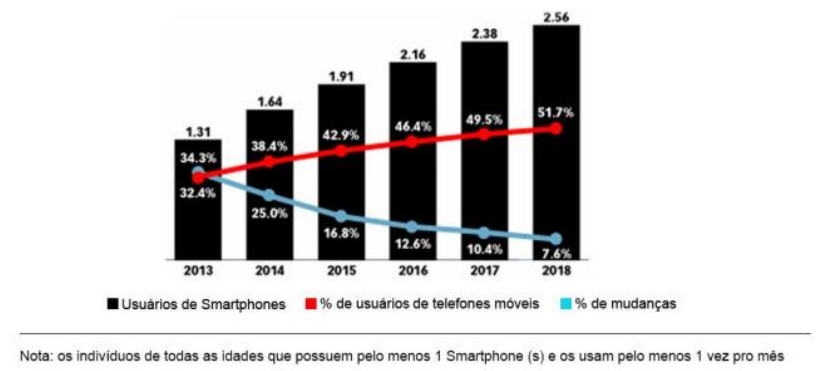

Figura 1: Número de usuários de Smartphones entre 2013 e 2018. Em bilhões. \% de usuários de telefone móvel e \% de mudança.

Parte dos dispositivos disponíveis no mercado, permitem ajustar as configurações do mesmo de acordo com a necessidade do usuário, assim pessoas com deficiência visual, motora, etc. podem optar pelo uso dos assistentes pessoais, que são adotados por alguns dos dispositivos encontrados no mercado, como a Cortana ${ }^{\circledR}$ do Windows Phone $®(\mathrm{Mi}-$ crosoft, 2015) e a Siri $®$ do iOS $®$ (Apple, 2013) que auxiliam o usuário em tarefas corriqueiras dos dispositivos - como enviar mensagens, fazer ligações, acessar a internet, etc. - através de comandos de voz.

Alguns destes programas ultrapassam seus objetivos e são amplamente utilizados, como o aplicativo que transforma texto em voz adotado pelos sistemas de GPS. O jogo Blind Domino associa algumas dessas ideias como o recurso de voz para a interação de cegos com smartphones. Ao utilizar o jogo, o indivíduo com deficiência pode aprender como usar tais aparelhos e com isso, ele terá maior autonomia e segurança quando se deparar com outros aplicativos.

\section{Trabalhos Relacionados}

A acessibilidade é um assunto de grande importância já que esta foi o meio construído para auxiliar as pessoas na inclusão social e digital. Por seu valor social, muitos autores discutem sobre ela colocando em evidência os métodos utilizados para se criar um ambiente totalmente acessível à qualquer pessoa, independentemente de suas diferenças.

Há aqueles autores que discutem sobre acessibilidade em ambientes específicos ou para pessoas com deficiências preestabelecidas:

A construção de uma sociedade de plena participação e igualdade tem como um de seus princípios a interação efetiva de todos os cidadãos. Nessa perspectiva, é fundamental a construção de políticas de inclusão para o reconhecimento da diferença e para desencadear uma revolução conceitual que conceba uma sociedade em que todos devem participar, com direito de igualdade e de acordo com suas especificidades. As novas tecnologias da informação e da comunicação encerram potencialidades positivas ao contribuírem cada vez mais para a integração de todos os cidadãos.”.(CONFORTO E SANTAROSA, 2002, p. 87).

Complementando a ideia de acessibilidade e seus benefícios:

A acessibilidade é uma qualidade, uma facilidade que desejamos ver e ter em todos os contextos e aspectos da atividade humana. Se a acessibilidade for (ou tiver sido) projetada sob os princípios do desenho universal, ela beneficia todas as pessoas, tenham ou não qualquer tipo de deficiência.(SASSAKI, 2009, p. 11). 
Conforto e Santarosa (apud Zúnica 1999) ainda, consideram que a acessibilidade envolve diferentes áreas e entre elas puderam citar: (1) a acessibilidade ao computador que é o envolvimento de softwares de acesso, incluindo as Ajudas Técnicas para uso generalizado de vários computadores e periféricos; (2) a acessibilidade ao Navegador, que podem ser desde os mais comuns como o Microsoftтm Internet Explorer e o Netscape Navigator. Porém, há o exemplo do navegador só de texto LYNX para cegos; (3) a acessibilidade ao planejamento de páginas WEB, que trabalha com o conteúdo, estrutura e formato, o ponto principal desta área é a escolha da ferramenta que será utilizada para desenvolvimento da página oferecendo mais possibilidade de opções de acessibilidade. Estes pontos são analisados no momento de criação dos sites, por parte de muitos desenvolvedores, que têm como intuito proporcionar um maior conforto aos usuários que acessarão as páginas.

Porém, nem sempre a falta de acesso é dada apenas por alguma deficiência, esta que também aparece por causa das barreiras existentes para muitos adquirirem equipamentos ou com a questão da usabilidade dos softwares.Segundo Menezes, Bonadia e Holanda (2009) essas barreiras se devem a falta de infraestrutura que permite o acesso à informação, lazer e etc. para os deficientes. Além da infraestrutura, a falta de recursos nas interfaces existentes e escassez de conteúdo em linguagem compreensível impedem o deficiente de usufruir do conteúdo disponível.

Os jogos assistivos foram criados ou adaptados para que o maior número de pessoas possam utilizá-los, esse tipo de aplicação demanda uma preocupação maior em sua produção, diferente dos demais. Cada ação, cada movimento, cada feedback deve ser pensado minuciosamente para que se tenha certeza que serão de fácil entendimento e execução.

Algumas aplicações assistivas, além de divertir o jogador, ajudam o mesmo a exercitar algumas funções cognitivas, como o caso do Audiogame Fuga de Faustino (2014), jogo voltado para o público com deficiência visual. Nele, o jogador deve percorrer um labirinto orientando-se através de sons 3D. Para os comandos, quem está jogando deve realizar movimentos que serão captados através de um Kinect, dispositivo que capta os movimentos do usuário, como esticar os braços para frente ou para cima, e os converte em comandos para o jogo, permitindo que este seja jogado sem que o jogador utilize de joysticks, teclados, mouse, etc.. Durante a fase tutorial, o jogador é treinado a identificar a direção dos sons ao seu redor e o que fazer caso tal som seja tocado durante uma fase do jogo. Esse treinamento pode facilmente ser levado do jogo para a vida real, sendo usado, por exemplo em um incêndio. Isso dá autonomia ao sujeito com deficiência, permitindo que ele fique mais independente em suas ações

Os jogos asisitvos não são exclusividade para consoles e computadores. Pode-se encontrar este tipo de jogo para outras plataformas, como é o exemplo do aplicativo TapBits Kim (2011), este permite ao jogador interagir com instrumentos musicais direto no smartphone, podendo criar sua música, repetir uma melodia tocada, etc. Nele, o usuário é guiado por sons, que o instrui como realizar as ações propostas. Esse jogo, como o Blind Domino pode ajudar o usuário a aprender como realizar tarefas em um dispositivo com tela sensível ao toque.

Contudo, a acessibilidade e os jogos assistivos, ambos caminhando em paralelo já são assuntos de grande interesse por parte dos pesquisadores. Porém, é muito difícil encontrar trabalhos em que os problemas enfrentados pelo portador de deficiência visual são 
relatados, pois a interação com o universo virtual, por parte dos cegos é uma tarefa complexa. Muitos estudiosos tratam a acessibilidade superficialmente, quando direcionado ao público com deficiência, deixando muitas vezes de citar os pontos de mudança. Entretanto, nossa pesquisa conseguiu apresentar alguns pontos que futuramente poderão ser úteis em novas investigações que serão relatadas no decorrer deste artigo.

\section{Metodologia}

Trata-se de uma pesquisa de natureza qualitativa e interpretativa, na área da Ciência da Computação com o interesse de investigar, interpretar, descrever e refletir sobre a inclusão digital das pessoas com deficiência visual no mundo do entretenimento.

O mesmo se desenvolveu de acordo com as seguintes etapas: 1) primeiramente, a fim de conhecer mais sobre acessibilidade virtual, foi realizada uma revisão bibliográfica; 2) em segundo, foi criado o projeto de software do aplicativo; 3 ) posteriormente, a partir do projeto uma primeira versão do jogo foi implementado; 4) a seguir realizamos uma sessão de testes com o público alvo, onde seguimos os passos: a) a fim de estabelecer contato entre os cegos apresentamos o jogo Blind Domino; b) explicamos o funcionamento; c) observamos a jogabilidade por parte dos deficientes; d)em último, analisamos a desenvoltura dos usuários na hora do jogo; 5) e por fim, houve um aprimoramento do jogo, em cima do que foi relatado durante o teste, criando assim uma segunda versão do Blind Domino.

\section{Desenvolvimento}

\subsection{Análise de Requisitos}

Para a análise de requisitos primeiramente fez-se uma pesquisa de mercado onde foi realizada uma busca por jogos para cegos, jogos para mobile e jogos de dominós para mobile. Esta pesquisa relatou que este foi o primeiro jogo criado que abrange as três categorias simultaneamente.

A segunda parte da pesquisa de mercado foi referente à busca da melhor linguagem de programação para o desenvolvimento do jogo. Após a mesma foi constatado que as linguagens que atenderiam as necessidades da aplicação seriam Java e Lua.

Após estudos sobre as vantagens e desvantagens de ambas, optou-se pela Lua, porque temíamos que Java não pudesse oferecer os recursos de áudio e imagem, estes que se tornariam vitais no futuro. Para o auxílio na programação em $L u a$ foi utilizado o editor Sublime Text 2 e o compilador Corona SDK, este para interpretar o código implementado e executar a aplicação, simulando um dispositivo móvel.

Depois da pesquisa de mercado foi realizado também uma pesquisa de campo onde foram feitos testes com um dominó físico, usando regras predefinidas. Como resultado desta pesquisa gerou uma análise que mostrou os erros que poderiam acontecer durante o jogo. Desta forma foi possível pensar em soluções para estes a fim de evitar erros futuros. 


\subsection{Projeto de Software}

Para o projeto de software foi escolhido o diagrama de caso de uso (Figura 2). Este foi escolhido de modo a facilitar a compreensão de como cada método iria trabalhar e interagir com o outro. Apresentando também como seria a comunicação do usuário com o jogo, observando todos os processos e quando estes ocorrem.

Para criar o diagrama foi utilizado o programa Star $U M L$, pois este apresenta uma interface simples com muitos recursos.

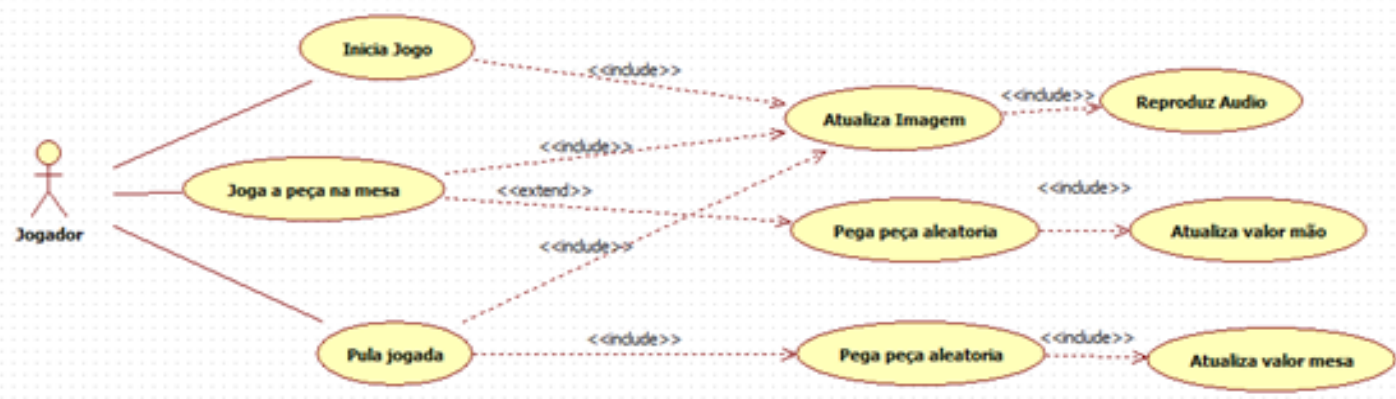

Figura 2: Diagrama de Casos de Uso

\subsection{Implementações}

Durante o desenvolvimento do jogo, alguns testes internos foram realizados para corrigir alguns erros e também para trocar algumas coisas da mecânica do jogo que se tornou muito complexo, já que no início o número de comandos estava ligeiramente elevado.

Depois de alguns meses de programação, foi possível criar o primeiro protótipo, (Figura 3). Este já tinha as exceções, as regras predefinidas e a mecânica já funcionando.

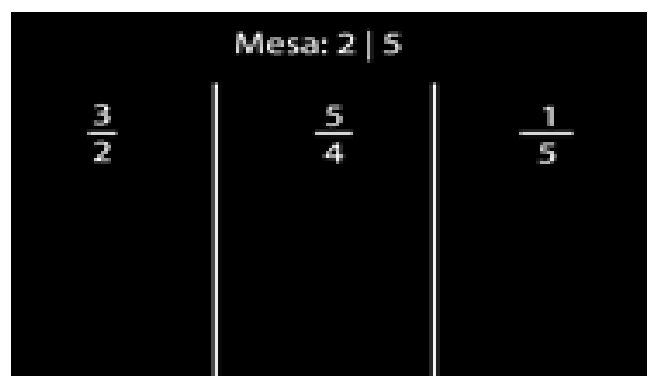

Figura 3: Primeiro Layout do jogo

Já com o primeiro protótipo em funcionamento, foi proposto uma primeira atualização deste, pois observou-se que ele não iria agradar uma pessoa sem deficiência visual, devido a sua interface sem apelo visual. Além do visual, um dos pontos que provocaram sua atualização foi o áudio mecanizado. O áudio usado originalmente foi gerado através da ferramenta on-line SOAR. Como o jogo depende totalmente de áudio, regravar o mesmo era necessário, agora com a voz de uma pessoa, que neste caso foi a Maria Aparecida Pereira Junqueira, autora deste artigo.

Esta nova versão do jogo apresenta uma interface mais convidativa, a fim de atingir um público diversificado, as pessoas com deficiência visual, auditiva, ou sem qualquer tipo de deficiência, além de um áudio mais claro e agradável. 


\subsection{Modo de Jogar}

Para que o jogo Blind Domino pudesse ser acessível às pessoas com deficiência visual, ele foi projetado baseado no áudio, ou seja, a pessoa irá escutar tudo aquilo que se passa no jogo. Outro ponto que foi atribuído ao jogo é a divisão da tela em três partes iguais onde cada uma das partes é uma das peças da mão do jogador.

Ao iniciar o jogo, o jogador recebe três e a mesa uma peça, todas obtidas aleatoriamente da matriz de peças. O jogador poderá então, optar por jogar uma de suas peças na mesa - caso elas combinem - ou então poderá passar a jogada, atualizando assim os valores da mesa. Para jogar uma peça na mesa basta o jogador deslizar o dedo na tela para cima - caso ele queira jogar o lado de cima da peça (Figura 4 - A) - ou para baixo (Figura 4 - B) - caso ele queira jogar o lado de baixo da peça. Se o jogador por acaso optar por pular a jogada ele precisa apenas deslizar o dedo na tela para o lado (Figura 5 - A). Na condição de esquecimento de quais são as suas peças ou quais são os valores da mesa é necessário apenas que ele disponha seu dedo na tela e pressione (Figura 5 - B).

O jogo será considerado ganho caso o jogador consiga utilizar todas as peças do dominó e o mesmo irá ser considerado perdido se sobrar alguma peça na mão do usuário, que não se encaixe com nenhum dos lados da mesa.

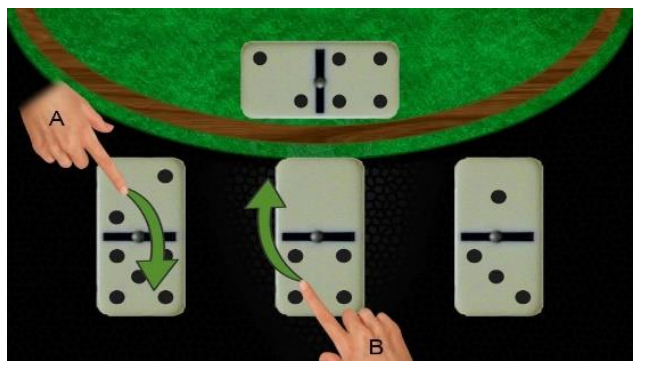

Figura 4: (A) Slide para baixo e (B) Slide para cima

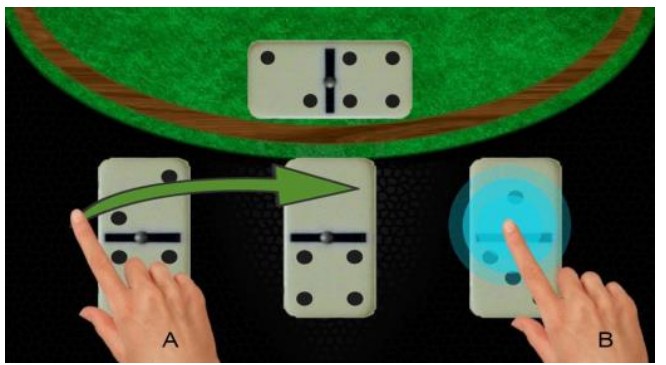

Figura 5: (A) Slide para o lado e (B) Toque longo

\section{Experimentos}

A fim de verificar se o jogo está apto para o uso de pessoas com deficiência visual, foram realizados testes e discussões posteriores com o intuito de descobrir problemas, através da observação do experimento e dos relatos dos participantes, e resolvê-los.

\subsection{Testes}

Este tópico é referente à apresentação de informações sobre o local da ocorrência dos testes, bem como a coleta de dados, os usuários envolvidos e os resultados. 

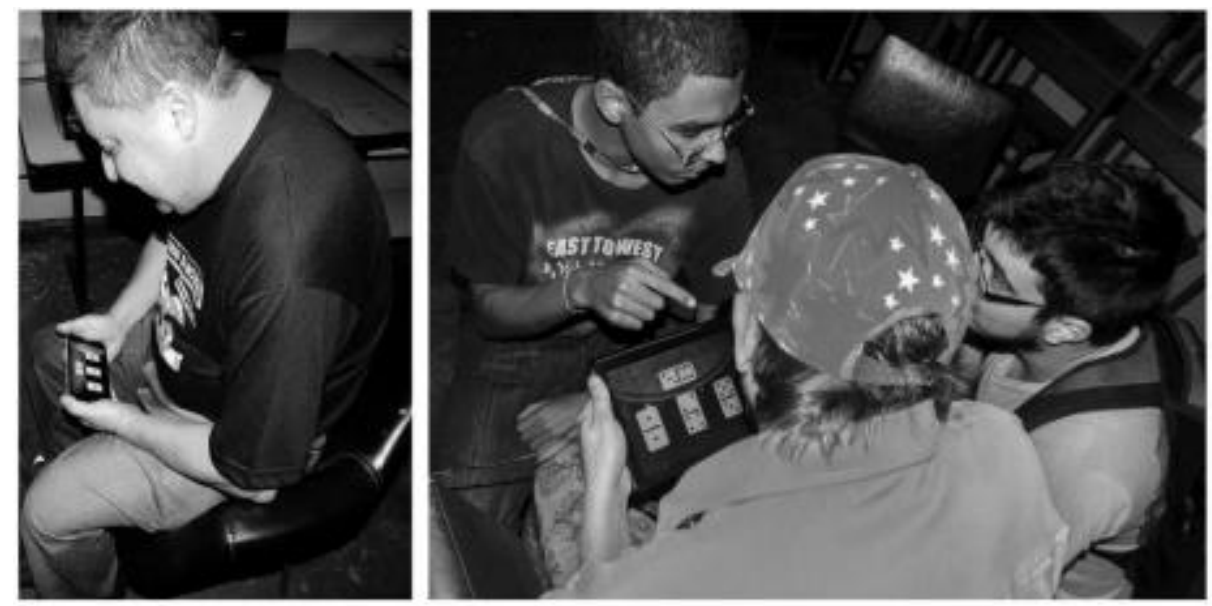

Figura 6: Participante durante os testes.

Os testes foram realizados na Associação Regional de Pessoas Portadoras de Deficiência de Barbacena, em Minas Gerais, que se encontra na Praça Adriana de Oliveira, $\mathrm{S} / \mathrm{N}$ - Rede Ferroviária, onde 12 indivíduos participaram do experimento descritos na figura 7.

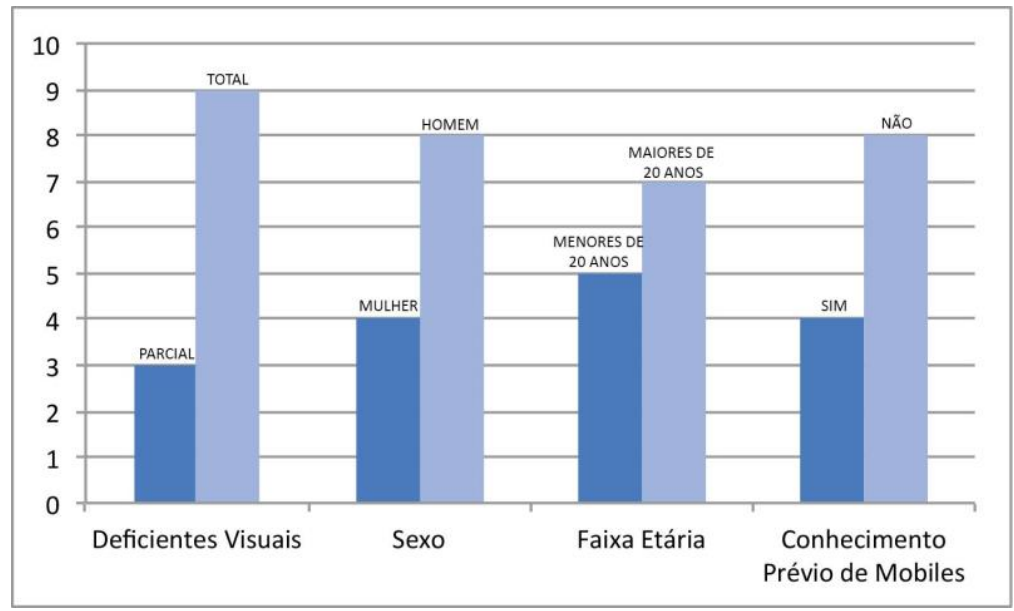

Figura 7: Gráfico indicativo, relação dos participantes do teste.

Para o teste com o aplicativo foram utilizados dois tipos de dispositivos, sendo dois modelos de Smartphones, um que apresentava botões físicos em sua lateral e outro que não os possuía. Para a coleta dos dados, logo após o teste com o software, foi utilizado um questionário de 10 perguntas dentre elas: "É fácil operar e controlar o jogo?", "Você encontrou algo que o deixa desconfortável?" e "Sobre os problemas encontrados, estes são referentes ao aplicativo ou ao aparelho?"

Os resultados obtidos após a coleta das informações expressaram o que os participantes gostaram do jogo, porém estes sentiram uma certa dificuldade quanto ao uso do dispositivo. Depois de uma análise dos dados, foi percebido que tais dificuldades eram as mesmas quando esse público utilizava outros dispositivos e aplicações.

No que diz respeito aos problemas com o uso dos aparelhos foram notados os seguintes pontos, a dificuldade de localização ou orientação no dispositivo e a saída acidental do aplicativo sem um feedback, que ocorria com o Smartphone sem botões físicos, pela ausência dos mesmos ou pela disposição destes que eram sensíveis ao toque no aparelho. 
Estas foram as maiores queixas e que atrapalhava significantemente o uso do mesmo por esse público.

Quanto à dificuldade no uso do aplicativo as pessoas que participaram do teste relataram ter problemas para guardar tanta informação a cada jogada. Então, para melhorar a situação, a mecânica do jogo foi modificada, agora permitindo que, independente da extremidade que se encontre o valor correspondente, o jogador poderá 'deslizá-la' tanto para cima, quanto para baixo, validando a jogada. Além dessa modificação, foi melhorado também o tutorial, tornando-o mais interativo e compreensível.

\subsection{Discussão dos resultados}

Com o estudo dos problemas enfrentados pelos cidadãos com deficiência visual e em cima dos resultados obtidos através dos testes (Figura 7), foi constatado que o índice de deficientes visuais com baixo ou nenhum letramento sobre dispositivos móveis é relativamente mais alto em relação àquelas que possuem conhecimento sobre os aparelhos mobile.

Pode se perceber também que, os participantes mais jovens (menores de 20 anos) tiveram uma facilidade maior com manuseio tanto do jogo quanto do dispositivo. E estes também tiveram uma predisposição maior para quererem utilizar tais ferramentas. Dentre os usuários mais jovens o índice de indivíduos com conhecimento prévio sobre aparelhos móveis também foi maior, sendo que $80 \%$ das mesmas já haviam tido algum contato com estes.

Podemos atribuir ambos os casos à falta de alfabetização virtual, dos elementos, causada pela escassez de softwares que atinja este grupo, já que tutoriais de jogos e outros aplicativos podem apresentar recursos gráficos, estabelecendo assim a estagnação do mesmo. Um outro fator é, a falta de recursos no mercado que os ensinem a usar dispositivos eletrônicos, dificultando ainda mais o uso de softwares, mesmo que este tenha sido projetado para eles.

\section{Conclusão}

De acordo com a ONU (Organização das Nações Unidas, 2010), cerca de 10\% da população mundial sofre de algum tipo de deficiência. Essa pequena parcela possui, como qualquer outra, os mesmos direitos de acesso à informação, entretenimento, educação e etc.. E para que isso seja possível, algumas mudanças devem ser feitas.

O mercado deve se reinventar. Dar variedade de produtos para esse público, pois aos poucos eles estão encontrando seu lugar e se superando. E, para o desenvolvimento dos mesmos, é mais do que certo que eles possuam aplicações e sistemas que deixem o seu dia-a-dia mais feliz, sendo um jogo, um aplicativo de mensagens, um player de músicas, dentre outros, projetados para que eles também consigam usufruir sem nenhum problema.

Através deste estudo, tendo como base a criação do Blind Domino entendemos um pouco de algumas das dificuldades enfrentadas pelo público com deficiência visual. Percebemos também, ao longo de todo o processo de pesquisa, implementação e testes que a criação de aplicativos acessíveis é uma tarefa árdua, porém não é impossível e os resultados são reconfortantes, devido a boa aprovação dos usuários. Com isso, podemos pensar em uma versão multiplayer, onde os usuários, além de se divertir, poderão interagir com outros jogadores. 
Por fim, os obstáculos são muitos, os recursos financeiros poucos, e a atenção mínima. Entretanto, somos jovens pesquisadores que buscam outras oportunidades, novos empreendimentos e enormes desafios. Ao longo dos testes do jogo, nos deparamos com um, mas acreditamos que com determinação, pesquisa e muito estudo conseguiremos adequar mais formas de diminuir a exclusão digital.

\section{Agradecimentos}

Os autores gostariam de agradecer à FAPEMIG (Fundação de Amparo à Pesquisa do estado de Minas Gerais) e ao PET (Programa de Educação Tutorial) pelo apoio financeiro oferecido para os mesmos.

\section{Referências Bibliográficas}

APPLE INC., 2013, Disponível em: <http://www.apple.com/ios/siri/?cid=oas-us $>$ Acesso em 23 de maio de 2015.

CONFORTO, D. e SANTAROSA, L. M. C. (2002). "Acessibilidade à WEB: Internet para todos." Informática na educação : teoria \& prática. Porto Alegre. Vol. 5, n. 2, p. 87-102.

EMARKETER, 2014. Disponível em: <http://www.emarketer.com/Article/2-BillionConsumers-Worldwide-Smartphones-by-2016/1011694>. Acesso em 29 de Maio de 2015.

FAUSTINO, P.R.C., MOREIRA, G.B.S.M., RAMALHO, M.M. E SILVA L.D., MACHADO A.F.V. (2014). "Development of a Game With Kinect For The Inclusion of Visually Impaired”. GAMEON Conference.

KIM, J., RICAURTE, J. (2011). “TapBeats: accessible and mobile casual gaming”. In: The proceedings of the 13th international ACM SIGACCESS conference on Computers and accessibility. ACM. p. 285-286.

MENEZES, E., BONADIA, G. C., HOLANDA, G. M. (2009). "Indicadores para a sociedade da informação: medindo as múltiplas barreiras à inclusão digital”. Disponível em: <http://www.cpqd.com.br/cadernosdetecnologia/Vol5_N1_jan_jun_ 2009/ pdf/artigo1.pdf $>$.

MICROSOFT INC. Disponível em <http://www.windowsphone.com/pt-br/how-to/wp8/ cortana/meet-cortana>. Acesso em 23 de maio de 2015.

ONU, 2010, A ONU e as pessoas com deficiência. Disponível em: $<$ http://www.onu.org.br/a-onu-em-acao/a-onu -e-as-pessoas-com-deficiencia/>.

SASSAKI, R. K. (2009). “Inclusão: acessibilidade no lazer, trabalho e educação”. Revista Nacional de Reabilitação (Reação), São Paulo, Ano XII, p. 10-16.

TORRES, E. F., MAZZONI, A. A., ALVES, J. B. M. (2002). "A acessibilidade à informação no espaço digital.” Ci. Inf., Brasília , v. 31, n. 3, p. 83-91.

ZUNICA, R. R. Deseño de Páginas WEB Acessibles. In: Jornada sobre Comunicación Aumentativa y Alternativa - ISAAC, 1., Espanha set. 1999. p.9-11 